\title{
Genome-wide Interaction Analysis of Menopausal Hormone Therapy Use and Breast Cancer Risk among 62,370 Women
}

Xiaoliang Wang ( $\nabla$ xwang23@fredhutch.org)

University of Washington

Pooja Kapoor

German Cancer Research Center

\section{Paul Auer}

University of Wisconsin-Milwaukee

Joe Dennis

University of Cambridge

Alison Dunning

University of Cambridge

Qin Wang

University of Cambridge

Michael Lush

University of Cambridge

Kyriaki Michailidou

Cyprus Institute of Neurology and Genetics

\section{Manjeet Bolla}

University of Cambridge

Kristan Aronson

Queen's University

\section{Rachel Murphy}

University of British Columbia

\section{Angela Brooks-Wilson}

BC Cancer Agency

\section{Derrick Lee}

St. Francis Xavier University

\section{Emilie Cordina-Duverger}

INSERM University Paris-Saclay

\section{Pascal Guénel}

INSERM University Paris-Saclay

\section{Thérèse Truong}

INSERM University Paris-Saclay

Claire Mulot

INSERM UMR-S1147 University Paris Sorbonne

Lauren Teras

American Cancer Society

Alpa Patel

American Cancer Society 


\section{Laure Dossus}

International Agency For Research On Cancer

\section{Rudolf Kaaks}

German Cancer Research Center

\section{Reiner Hoppe}

Dr. Margarete Fischer-Bosch-Institute of Clinical Pharmacology

\section{Wing-Yee Lo}

Dr. Margarete Fischer-Bosch-Institute of Clinical Pharmacology

\section{Thomas Brüning}

Ruhr University Bochum

\section{Ute Hamann}

German Cancer Research Center

\section{Kamila Czene}

Karolinska Institute

\section{Marike Gabrielson}

Karolinska Institute

\section{Per Hall}

Karolinska Institute

\section{Mikael Eriksson}

Karolinska Institute

\section{Audrey Jung}

German Cancer Research Center

\section{Heiko Becher}

University Medical Center Hamburg-Eppendorf

\section{Fergus Couch}

Mayo Clinic

\section{Nicole Larson}

Mayo Clinic

Janet Olson

Mayo Clinic

\section{Kathryn Ruddy}

Mayo Clinic

\section{Graham Giles}

Cancer Council Victoria

\section{Robert Maclnnis}

Cancer Council Victoria

Melissa Southey

Monash University

\section{Loic Le Marchand}

University of Hawaii System

\section{Lynne Wilkens}

University of Hawaii System

\section{Christopher Haiman}

University of Southern California

\section{Håkan Olsson}


Lund University

Annelie Augustinsson

Lund University

Ute Krüger

Lund University

Philippe Wagner

Lund University

Christopher Scott

Mayo Clinic

Stacey Winham

Mayo Clinic

Celine Vachon

Mayo Clinic

Charles Perou

University of North Carolina at Chapel Hill

Andrew Olshan

University of North Carolina at Chapel Hill

Melissa Troester

University of North Carolina at Chapel Hill

David Hunter

University of Oxford

Heather Eliassen

Harvard T.H. Chan School of Public Health

Rulla Tamimi

Weill Cornell Medicine

Kristen Brantley

Brigham and Women's Hospital

Irene Andrulis

Lunenfeld-Tanenbaum Research Institute

Jonine Figueroa

University of Edinburgh

Stephen Chanock

National Cancer Institute

Thomas Ahearn

National Cancer Institute

Montserrat García-Closas

National Cancer Institute

Gareth Evans

University of Manchester

William Newman

University of Manchester

Elke van Veen

University of Manchester

Anthony Howell

University of Manchester 


\section{Alicja Wolk}

Karolinska Institute

\section{Niclas Håkansson}

Karolinska Institute

\section{Hoda Anton-Culver}

University of California, Irvine

\section{Argyrios Ziogas}

University of California, Irvine

\section{Michael Jones}

Institute of Cancer Research

\section{Nick Orr}

Queen's University Belfast

\section{Minouk Schoemaker}

Institute of Cancer Research

\section{Anthony Swerdlow}

Institute of Cancer Research

\section{Cari Kitahara}

National Cancer Institute

\section{Martha Linet}

National Cancer Institute

\section{Ross Prentice}

Fred Hutchinson Cancer Research Center

\section{Douglas Easton}

University of Cambridge

\section{Roger Milne}

Cancer Council Victoria

\section{Peter Kraft}

Harvard T.H. Chan School of Public Health

Jenny Chang-Claude

German Cancer Research Center

\section{Sara Lindström}

University of Washington

\section{Research Article}

Keywords: breast cancer risk, gene-environment interaction, genome-wide association study, menopausal hormone therapy

Posted Date: July 2nd, 2021

DOI: https://doi.org/10.21203/rs.3.rs-532921/v2

License: (c) (i) This work is licensed under a Creative Commons Attribution 4.0 International License. Read Full License 
Version of Record: A version of this preprint was published at Scientific Reports on April 13th, 2022. See the published version at https://doi.org/10.1038/s41598-022-10121-2. 


\section{Abstract}

Background: Use of menopausal hormone therapy $(\mathrm{MHT})$ is associated with increased risk for breast cancer. However, the relevant mechanisms and its interaction with genetic variants are not fully understood.

Methods: We conducted a genome-wide interaction analysis between MHT use and genetic variants for breast cancer risk in 27,585 cases and 34,785 controls from 26 observational studies. All women were post-menopausal and of European ancestry. Multivariable logistic regression models were used to test for multiplicative interactions between genetic variants and current MHT use. We considered interaction $\mathrm{p}$-values $<5 \times 10^{-8}$ as genome-wide significant, and $\mathrm{p}$ values $<1 \times 10^{-5}$ as suggestive. Linkage disequilibrium (LD)-based clumping was performed to identify independent candidate variants.

Results: None of the 9.7 million genetic variants tested for interactions with MHT use reached genome-wide significance. Only 213 variants, representing 18 independent loci, had $p$-values $<1 \times 10^{5}$. The strongest evidence was found for rs4674019 ( $p$-value $\left.=2.27 \times 10^{-7}\right)$, which showed genome-wide significant interaction $\left(p\right.$-value $\left.=3.8 \times 10^{-8}\right)$ with current MHT use when analysis was restricted to population-based studies only. Limiting the analyses to combined estrogenprogesterone MHT use only or to estrogen receptor (ER) positive cases did not identify any genome-wide significant evidence of interactions.

Conclusions: In this large genome-wide SNP-MHT interaction study of breast cancer, we found no strong support for common genetic variants modifying the effect of $\mathrm{MHT}$ on breast cancer risk. These results suggest that common genetic variation has limited impact on the observed MHT-breast cancer risk association.

\section{Introduction}

Breast cancer is one of the most common cancers in women. There were 268,600 new cases and 41,760 deaths due to breast cancer estimated in the U.S. in $2019^{1}$. The use of menopausal hormone therapy (MHT) is associated with up to $23 \%$ increased risk of breast cancer. MHT use has been reduced among postmenopausal women since the report by the Women's Health Initiative (WHI) clinical trial and observational study ${ }^{2,3}$ which has been subsequently confirmed by other studies and meta-analyses ${ }^{4,5}$. Breast cancer risk increases with longer duration of use ${ }^{6}$, and is higher for combined estrogen-progesterone MHT (EPT) use as compared with estrogen-only (ET) regimens ${ }^{4,5}$. Additionally, the association between MHT use and breast cancer may also differ by tumor molecular subtype. A prospective cohort study in UK found that current MHT use was associated with increased risk for estrogen receptor positive (ER+) breast cancers, but not with ER- breast cancers ${ }^{7}$. Several other observational studies also found that MHT use was associated with elevated risk of ER + breast cancer ${ }^{8-12}$.

The biological mechanisms underlying the effect of MHT use on breast cancer risk is not fully understood. One proposed mechanism is that higher estrogen and progesterone levels increase the proliferation of breast epithelial cells, which results in accumulation of genetic mutations and insufficient DNA repair ${ }^{13}, 14$, and therefore induces mutagenesis $^{15,16}$. Genome-wide association studies (GWAS) have identified over 200 single nucleotide polymorphisms (SNPs) that are associated with invasive breast cancer risk ${ }^{17-19}$. Further analyses based on these GWAS findings have identified several genes that might interact with $\mathrm{MHT}$ use on breast cancer risk, including SNPs regulating the fibroblast growth factor receptor two (FGFR2) gene ${ }^{20}$, as well as SNPs close to the Kruppel like factor 4 (KLF4) gene and the

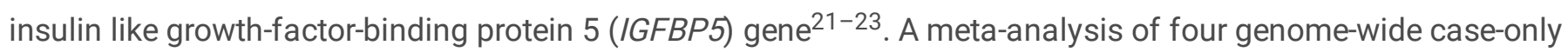
interaction studies found suggestive evidence of interactions between MHT use and SNPs in genes related to 
transmembrane signaling and immune cell activation ${ }^{24}$. However, none of the findings reached genome-wide significance.

In the present study, we performed a comprehensive genome-wide interaction analysis of current MHT use by pooling individual-level data from 26 epidemiological studies. We also performed genome-wide interaction analysis of MHT use on ER + breast cancer specifically.

\section{Methods}

\section{Study population and data collection}

Individual level data were pooled from 26 epidemiological studies, including eight population-based case-control studies, 13 prospective cohort studies and five studies with mixed design from the Breast Cancer Association Consortium (BCAC) (Table S1). Data collection instruments for individual studies have been described previously ${ }^{19,23}$. Breast cancer cases were defined as incident invasive or in-situ breast tumors, confirmed by medical records, pathological reports or death certificates. Cases of benign breast disease or cases diagnosed more than five years before study enrollment were excluded.

Participants were excluded if they were male, pre-menopausal, of non-European ancestry, with unknown age at reference date, or missing information on MHT use. Reference date was defined as date of diagnosis for cases, and date of interview for controls. Menopausal status was reported at time of interview. For women with missing menopausal status, we assumed postmenopausal status for those who were $>54$ years old. Only studies with information on MHT use in at least 150 breast cancer cases and 150 controls were included in the data analysis.

\section{Ethnical approval and consent to participate}

All participating studies were approved by the relevant ethics committees and informed consent was obtained from study participants.

\section{Menopausal hormone therapy use definition}

MHT use was defined as use for at least three months of any type of MHT, including EPT and ET. Current MHT use was defined as use at, or within the six months prior to the reference date. Former MHT use was defined as women who had a history of using MHT but had quit more than six months prior to the reference date.

\section{Genotyping}

Samples were genotyped by the Illumina custom iSelect genotyping array (iCOGs) ${ }^{25,26}$ or the Illumina OncoArray $500 \mathrm{~K}$ (OncoArray) ${ }^{19,27}$. Details on genotyping, imputation and quality-control checks have been published previously ${ }^{19,26}$. For these analyses, 9,680 cases and 10,598 controls were genotyped using iCOGs, and 17,905 cases and 24,187 controls were genotyped using OncoArray. Both datasets were imputed to the 1000 Genomes Phase 3 release ${ }^{28}$. For samples that were genotyped on both iCOGs and OncoArray, OncoArray data was used. SNPs were excluded if imputation $r^{2}<0.5$ for iCOGs, and $r^{2}<0.8$ for OncoArray. A total of 9,661,037 genetic variants (SNPs and indels) were included for analysis in both datasets.

\section{Statistical Analysis}

We used multivariable logistic regression models to test for interaction between each genetic variant and current $\mathrm{MHT}$ use (relative to never users) on breast cancer risk, adjusting for age at reference date, study, former MHT use, an 
indicator for population-based study design, an interaction term of study design indicator and current MHT use, and principal components to account for potential population stratification ${ }^{29}$, thus fitting a model of the form:

$$
\begin{gathered}
\text { logit }[\operatorname{Pr}(D)]=\alpha+\beta_{c} \text { CurrentMHT }+\beta_{g} S N P+\beta_{g c} S N P \times \text { CurrentMHT } \\
+\beta_{a} \text { age }+\sum_{i} \beta_{i} \text { study }_{i}+\beta_{f} \text { FormerMHT }+\beta_{p} \text { PopulationBased } \\
+\beta_{p c} \text { PopulationBased } \times \text { CurrentMHT }+\sum_{j} \beta_{j} P C_{j}
\end{gathered}
$$

Each genetic variant was assessed as a continuous variable in a log-additive odds ratio model. For genetic variants that were not directly genotyped, the expected number of copies of the variant allele ("dosage") was used ${ }^{30}$. OncoArray and iCOGs datasets were analyzed separately, and platform-specific interaction parameter estimates $\left(\beta_{g c}\right)$ were combined using METAL ${ }^{31}$ to obtain summary estimates for each SNP. Similar analyses were also performed for EPT use only and for ER + breast cancer. Q-Q plots were used to assess whether the distribution of the p-values indicated genomic inflation.

For variants reaching suggestive evidence of interaction $\left(\mathrm{p}<1 \times 10^{-5}\right)$, we performed linkage disequilibrium (LD)-based clumping to identify independent loci that might interact with MHT use on breast cancer risk (SWISS version 1.0.05b). SNPs in LD ( ${ }^{2}>0.1$ based on the build-in 1000G_2014-11_EUR) within $1 \mathrm{Mb}$ from the most significantly associated SNP were removed so that independent SNPs remained in each region.

We also performed sensitivity analysis among patients from the population-based studies only. All analyses were performed using $\mathrm{R}$ version 3.6.1 unless otherwise specified.

\section{Results}

A total of 62,370 post-menopausal women from 26 studies ( 27,585 cases and 34,785 controls), were included in the analyses (Table S1). Cases were slightly older (mean age: 64 years) than controls (mean age: 63 years). Current use of MHT was more common among breast cancer cases (34\%) than controls (28\%), showing a suggestive increased breast cancer risk $(\mathrm{OR}=1.16 ; 95 \% \mathrm{Cl}$ : 0.99, 1.36; Fig. 1A). A total of 20,131 cases and 22,601 controls from 18 studies also had information on current use of EPT. Current EPT use was more common among cases (19\%) than controls (13\%) and was associated with an estimated $48 \%$ risk increase of breast cancer, compared to non-EPT users (OR: $1.48 ; 95 \% \mathrm{Cl}$ : 1.29, 1.70; Fig. 1B).

A total of 9,661,271 SNPs and indels were successfully imputed from both the OncoArray and iCOGs genotyping platforms and were included in the meta-analysis. We did not observe any interactions between variants and current MHT use at genome-wide significance level ( $p$-value $<5 \times 10^{-8}$, Fig. 2A). 213 SNPs had suggestive evidence of interaction with MHT use on breast cancer risk ( $\mathrm{p}$-value $<1 \times 10^{-5}$ ). After LD-based clumping, 18 independent SNPs remained, none of which were in LD with currently known breast cancer risk GWAS loci (Table 1). The strongest evidence of interaction was for SNP rs4674019, located at chromosome $2 q 35$ ( $p$-value $\left.=2.27 \times 10^{-7}\right)$. When restricting the analyses to population-based studies only (23,063 cases and 30,250 controls), this same SNP rs4674019 showed statistically significantly interaction with current MHT use on breast cancer risk ( $p$-value $=3.75 \times 10^{-8}$; Figure S1). 
Table 1

Independent genetic variants with suggestive interactions of current MHT use on breast cancer risk after LD-based clumping

\begin{tabular}{|c|c|c|c|c|c|c|c|c|c|}
\hline SNP rsid & Chr & Position & $\mathrm{A} 1$ & $\mathrm{~A} 2$ & EAF & Nearby Genes & OR & $95 \% \mathrm{Cl}$ & P-value \\
\hline rs4674019 & 2 & 216601295 & A & G & 0.05 & LINC00607 & 0.74 & $\begin{array}{l}(0.66 \\
0.83)\end{array}$ & $\begin{array}{l}2.27 \mathrm{E}- \\
07\end{array}$ \\
\hline rs12600110 & 16 & 962154 & $\mathrm{~T}$ & C & 0.38 & LMF1 & 1.14 & $\begin{array}{l}(1.08, \\
1.20)\end{array}$ & $\begin{array}{l}5.11 \mathrm{E}- \\
07\end{array}$ \\
\hline rs548302406 & 2 & 120097151 & $\mathrm{~T}$ & TA & 0.35 & C2orf76 & 0.86 & $\begin{array}{l}(0.81 \\
0.92)\end{array}$ & $\begin{array}{l}8.03 \mathrm{E}- \\
07\end{array}$ \\
\hline rs117199302 & 11 & 77378563 & $\mathrm{~T}$ & C & 0.02 & $R S F 1$ & 0.60 & $\begin{array}{l}(0.49 \\
0.73)\end{array}$ & $\begin{array}{l}8.82 \mathrm{E}- \\
07\end{array}$ \\
\hline rs150004705 & 7 & 147063496 & $A$ & G & 0.01 & CNTNAP2 & 0.57 & $\begin{array}{l}(0.46 \\
0.72)\end{array}$ & $\begin{array}{l}9.13 \mathrm{E}- \\
07\end{array}$ \\
\hline rs188419699 & 7 & 6674441 & G & $A$ & 0.99 & ZNF853 & 0.40 & $\begin{array}{l}(0.27 \\
0.58)\end{array}$ & $\begin{array}{l}2.16 \mathrm{E}- \\
06\end{array}$ \\
\hline rs12600110 & 2 & 189608701 & C & $\mathrm{T}$ & 0.99 & $\begin{array}{l}\text { DIRC1, } \\
\text { LOC105373790 }\end{array}$ & 0.48 & $\begin{array}{l}(0.36 \\
0.66)\end{array}$ & $\begin{array}{l}3.26 \mathrm{E}- \\
06\end{array}$ \\
\hline rs11738429 & 5 & 36167878 & G & $A$ & 0.19 & SKP2 & 1.17 & $\begin{array}{l}(1.09 \\
1.25)\end{array}$ & $\begin{array}{l}4.09 \mathrm{E}- \\
06\end{array}$ \\
\hline rs13121484 & 4 & 182999291 & $A$ & G & 0.33 & AC108142.1 & 1.14 & $\begin{array}{l}(1.08, \\
1.21)\end{array}$ & $\begin{array}{l}5.02 \mathrm{E}- \\
06\end{array}$ \\
\hline rs74617030 & 2 & 206040628 & G & GA & 0.55 & PARD3B & 1.13 & $\begin{array}{l}(1.07 \\
1.19)\end{array}$ & $\begin{array}{l}5.90 \mathrm{E}- \\
06\end{array}$ \\
\hline rs146251672 & 3 & 64290001 & G & C & 0.98 & PRICKLE2, LRRN1 & 1.50 & $\begin{array}{l}(1.26, \\
1.78)\end{array}$ & $\begin{array}{l}6.08 \mathrm{E}- \\
06\end{array}$ \\
\hline rs560643086 & 1 & 204318668 & C & $\mathrm{CA}$ & 0.75 & PLEKHA6 & 1.16 & $\begin{array}{l}(1.09 \\
1.24)\end{array}$ & $\begin{array}{l}6.46 \mathrm{E}- \\
06\end{array}$ \\
\hline rs79001083 & 8 & 106538183 & $A$ & $\mathrm{C}$ & 0.05 & ZFPM2 & 1.30 & $\begin{array}{l}(1.16, \\
1.46)\end{array}$ & $\begin{array}{l}7.12 \mathrm{E}- \\
06\end{array}$ \\
\hline rs7900145 & 10 & 4933685 & $\mathrm{~T}$ & G & 0.24 & $A K R 1 C 6 P$ & 1.15 & $\begin{array}{l}(1.08, \\
1.22)\end{array}$ & $\begin{array}{l}7.75 \mathrm{E}- \\
06\end{array}$ \\
\hline rs375101296 & 11 & 78180810 & C & CAG & 0.94 & NARS2 & 0.77 & $\begin{array}{l}(0.69 \\
0.86)\end{array}$ & $\begin{array}{l}8.23 \mathrm{E}- \\
06\end{array}$ \\
\hline rs72692777 & 9 & 10011536 & $\mathrm{~T}$ & $\mathrm{C}$ & 0.02 & PTPRD & 0.70 & $\begin{array}{l}(0.59 \\
0.82)\end{array}$ & $\begin{array}{l}8.86 \mathrm{E}- \\
06\end{array}$ \\
\hline rs142227065 & 4 & 132518511 & $\mathrm{~T}$ & TA & 0.001 & $R P 11-314 N 14.1$ & 0.22 & $\begin{array}{l}(0.11 \\
0.43)\end{array}$ & $\begin{array}{l}9.07 \mathrm{E}- \\
06\end{array}$ \\
\hline rs10015072 & 4 & 31386277 & $\mathrm{~T}$ & $\mathrm{C}$ & 0.836 & $R P 11-315 A 17.1$ & 1.18 & $\begin{array}{l}(1.10 \\
1.27)\end{array}$ & $\begin{array}{l}9.67 \mathrm{E}- \\
06\end{array}$ \\
\hline \multicolumn{10}{|c|}{$\begin{array}{l}\text { * Chr: chromosome; A1: reference allele; A2: alternative allele; EAF: estimated allele frequency for alternative allele; } \\
\text { OR: odds ratios error per alternative allele with current menopausal hormone therapy use on breast cancer risk; } 95 \% \\
\text { Cl: corresponding } 95 \% \text { confidence intervals; }\end{array}$} \\
\hline
\end{tabular}


Similarly, we did not observe any genome-wide significant interactions between SNPs and combined EPT use on breast cancer risk (Fig. 2B). There were 71 SNPs that reached suggestive significance level at $p$-value $<1 \times 10^{-5}$. After LD-based clumping, 21 independent SNPs showed suggestive interactions (Table 2). The strongest evidence of interaction was for SNP rs4865075, located on chromosome $4 q 12\left(p\right.$-value $\left.=5.5 \times 10^{-7}\right)$. Sensitivity analysis using population-based studies only did not find statistically significant interactions. 
Table 2

Independent genetic variants with suggestive interaction of current combined EPT use on breast cancer after LD-based clumping

\begin{tabular}{|c|c|c|c|c|c|c|c|c|c|}
\hline SNP rsid & Chr & Position & A1 & A2 & EAF & $\begin{array}{l}\text { Nearby } \\
\text { genes }\end{array}$ & OR & $\begin{array}{l}95 \% \\
\mathrm{Cl}\end{array}$ & $\begin{array}{l}\mathrm{P} \text { - } \\
\text { value }\end{array}$ \\
\hline rs4865075 & 4 & 57113130 & $A$ & G & 0.76 & KIAA1211 & 1.25 & $\begin{array}{l}(1.14, \\
1.36)\end{array}$ & $\begin{array}{l}5.50 \mathrm{E}- \\
07\end{array}$ \\
\hline rs7519793 & 1 & 147301176 & C & $\mathrm{T}$ & 0.40 & $\begin{array}{l}R P 11- \\
433 \mathrm{~J} 22.3, \\
R P 11- \\
314 \mathrm{~N} 2.2\end{array}$ & 1.21 & $\begin{array}{l}(1.12, \\
1.31)\end{array}$ & $\begin{array}{l}1.59 \mathrm{E}- \\
06\end{array}$ \\
\hline rs4871847 & 8 & 22964316 & $A$ & G & 0.30 & TNFRSF10C & 0.82 & $\begin{array}{l}(0.85, \\
0.89)\end{array}$ & $\begin{array}{l}1.77 \mathrm{E}- \\
06\end{array}$ \\
\hline rs2165698 & 13 & 88558039 & $\mathrm{~T}$ & C & 0.54 & $\begin{array}{l}\text { TET1P1, } \\
\text { RP11- } \\
545 P 6.2\end{array}$ & 1.22 & $\begin{array}{l}(1.12, \\
1.33)\end{array}$ & $\begin{array}{l}2.76 \mathrm{E}- \\
06\end{array}$ \\
\hline rs34954573 & 3 & 76118773 & CT & C & 0.56 & ROBO2 & 0.82 & $\begin{array}{l}(0.76, \\
0.89)\end{array}$ & $\begin{array}{l}3.17 \mathrm{E}- \\
06\end{array}$ \\
\hline rs10836138 & 11 & 33996495 & C & $\mathrm{T}$ & 0.47 & $\begin{array}{l}\text { LMO2, } \\
\text { CAPRIN1 }\end{array}$ & 0.83 & $\begin{array}{l}(0.77 \\
0.90)\end{array}$ & $\begin{array}{l}3.37 \mathrm{E}- \\
06\end{array}$ \\
\hline rs4844958 & 1 & 210361388 & A & G & 0.47 & $\begin{array}{l}\text { SYT14, } \\
\text { SERTAD4- } \\
\text { AS1 }\end{array}$ & 1.20 & $\begin{array}{l}(1.11, \\
1.30)\end{array}$ & $\begin{array}{l}3.45 \mathrm{E}- \\
06\end{array}$ \\
\hline rs145119792 & 4 & 138681096 & G & $\mathrm{T}$ & 0.99 & $\begin{array}{l}R P 13- \\
884 E 18.4, \\
R P 11- \\
793 B 23.1\end{array}$ & 2.61 & $\begin{array}{l}(1.74, \\
3.91)\end{array}$ & $\begin{array}{l}3.71 \mathrm{E}- \\
06\end{array}$ \\
\hline rs2372593 & 2 & 216596263 & G & A & 0.93 & LINC00607 & 1.42 & $\begin{array}{l}(1.22, \\
1.66)\end{array}$ & $\begin{array}{l}4.52 \mathrm{E}- \\
06\end{array}$ \\
\hline rs1359939 & 1 & 177820861 & G & A & 0.68 & $\begin{array}{l}\text { RP11- } \\
\text { 63B19.1, } \\
\text { SEC16B }\end{array}$ & 1.22 & $\begin{array}{l}(1.12, \\
1.33)\end{array}$ & $\begin{array}{l}4.71 \mathrm{E}- \\
06\end{array}$ \\
\hline rs1398476 & 8 & 5608189 & C & $A$ & 0.79 & $\begin{array}{l}R P 11- \\
281 H 11.1, \\
R P 11- \\
728 L 1.1\end{array}$ & 0.79 & $\begin{array}{l}(0.81 \\
0.87)\end{array}$ & $\begin{array}{l}4.81 \mathrm{E}- \\
06\end{array}$ \\
\hline rs148904951 & 12 & 78267629 & $\mathrm{~T}$ & G & 0.03 & NAV3 & 2.05 & $\begin{array}{l}(1.51, \\
2.78)\end{array}$ & $\begin{array}{l}4.90 \mathrm{E}- \\
06\end{array}$ \\
\hline rs41380949 & 3 & 105175646 & $A$ & G & 0.10 & ALCAM & 1.36 & $\begin{array}{l}(1.19, \\
1.55)\end{array}$ & $\begin{array}{l}5.11 \mathrm{E}- \\
06\end{array}$ \\
\hline rs116807456 & 1 & 232593292 & $A$ & G & 0.02 & SIPA1L2 & 0.49 & $\begin{array}{l}(0.36, \\
0.66)\end{array}$ & $\begin{array}{l}5.76 \mathrm{E}- \\
06\end{array}$ \\
\hline rs79505632 & 8 & 11079796 & C & G & 0.05 & $\begin{array}{l}\text { AF131215.8, } \\
\text { LINC00529 }\end{array}$ & 0.66 & $\begin{array}{l}(0.55 \\
0.79)\end{array}$ & $\begin{array}{l}6.17 \mathrm{E}- \\
06\end{array}$ \\
\hline
\end{tabular}

* SNP: single nucleotide polymorphism; Chr: chromosome; A1: reference allele; A2: alternative allele; EAF: estimated allele frequency for alternative allele; OR: odds ratios per alternative allele with current combined estrogenprogesterone hormone therapy use on breast cancer risk; $95 \% \mathrm{Cl}$ : corresponding $95 \%$ confidence intervals;

** rsid and position are based on the Genome Reference Consortium Human genome build 37. 


\begin{tabular}{|c|c|c|c|c|c|c|c|c|c|}
\hline SNP rsid & Chr & Position & A1 & A2 & EAF & $\begin{array}{l}\text { Nearby } \\
\text { genes }\end{array}$ & OR & $\begin{array}{l}95 \% \\
\mathrm{Cl}\end{array}$ & $\begin{array}{l}\mathrm{P} \text { - } \\
\text { value }\end{array}$ \\
\hline rs146727380 & 3 & 21750977 & GAAAAC & GAAAACAAAAC & 0.51 & ZNF385D & 0.82 & $\begin{array}{l}(0.76 \\
0.90)\end{array}$ & $\begin{array}{l}6.61 \mathrm{E}- \\
06\end{array}$ \\
\hline rs146444598 & 6 & 29912227 & TGGA & $\mathrm{T}$ & 0.52 & $H L A-A$ & 1.19 & $\begin{array}{l}(1.10, \\
1.29)\end{array}$ & $\begin{array}{l}6.85 \mathrm{E}- \\
06\end{array}$ \\
\hline rs9690705 & 7 & 151595436 & G & $A$ & 0.42 & $\begin{array}{l}\text { PRKAG2- } \\
\text { AS1, RNU6- } \\
604 P\end{array}$ & 1.20 & $\begin{array}{l}(1.11, \\
1.29)^{\prime}\end{array}$ & $\begin{array}{l}7.46 \mathrm{E}- \\
06\end{array}$ \\
\hline rs77773073 & 3 & 44919409 & G & $A$ & 0.86 & $\begin{array}{l}\text { TGM4, } \\
\text { LRRN1 }\end{array}$ & 1.28 & $\begin{array}{l}(1.15, \\
1.43)\end{array}$ & $\begin{array}{l}7.65 \mathrm{E}- \\
06\end{array}$ \\
\hline rs1772028 & 14 & 101693861 & C & G & 0.49 & $\begin{array}{l}\text { RP11-8L8.1, } \\
\text { CTD- } \\
2561 F 5.1\end{array}$ & 0.84 & $\begin{array}{l}(0.78, \\
0.91)\end{array}$ & $\begin{array}{l}9.16 \mathrm{E}- \\
06\end{array}$ \\
\hline rs7522223 & 1 & 25217994 & $\mathrm{~T}$ & $\mathrm{C}$ & 0.15 & $\begin{array}{l}\text { CLIC4, } \\
R U N X 3\end{array}$ & 0.78 & $\begin{array}{l}(0.70 \\
0.87)\end{array}$ & $\begin{array}{l}9.26 \mathrm{E}- \\
06\end{array}$ \\
\hline \multicolumn{10}{|c|}{$\begin{array}{l}\text { * SNP: single nucleotide polymorphism; Chr: chromosome; A1: reference allele; A2: alternative allele; EAF: estimated } \\
\text { allele frequency for alternative allele; OR: odds ratios per alternative allele with current combined estrogen- } \\
\text { progesterone hormone therapy use on breast cancer risk; } 95 \% \mathrm{Cl} \text { : corresponding } 95 \% \text { confidence intervals; }\end{array}$} \\
\hline
\end{tabular}

Restricting our cases to those with ER + breast cancer did not result in any genome-wide significant findings (Figures S2S3).

\section{Discussion}

In this large genome-wide analysis of postmenopausal women of European ancestry, we did not identify any genetic variants that were strong modifiers of the association between current MHT use on breast cancer risk. Although the interaction between SNP rs4674019 and current MHT use was statistically significant among population-based studies only, the variate allele frequency is relatively rare $(\mathrm{EAF}=5 \%)$ and needs further validation.

Consistent with previous literature $2,3,32$, we found that current use of MHT, and in particular current EPT use, was associated with an increased risk of breast cancer for postmenopausal women. The mechanisms underlying this association are not fully understood. It has been hypothesized that estrogen stimulates cell proliferation through ERamediated hormone activity and increases mutation rates through a cytochrome P450-mediated metabolic activation that results in DNA damage ${ }^{33}$. In addition, the risk associated with ER + breast cancer is substantially higher than for ERbreast cancer, particularly for EPT use, suggesting an ER-dependent pathway ${ }^{5}$. In vitro and in vivo studies found that estradiol and 4-OH-estradiol, metabolites of estrogen, may induce mutations and damage DNA by forming DNA adducts to bind to adenine and guanine on the DNA backbone ${ }^{34,35}$. The role of progestogens in human breast carcinogenesis is less clear, although it has been suggested that synthetic progestogens are pro-proliferative and may thus promote cancer cell growth ${ }^{36,37}$.

Although MHT use has been found to be associated with increased breast cancer risk in both epidemiologic and experimental studies, no published studies to date have identified genome-wide significant interactions for breast cancer risk between candidate single variants and $\mathrm{MHT}$ use among postmenopausal women ${ }^{38,39}$. In a previous two-stage GWAS interaction analysis among $\sim 2,700$ cases and $~ 2,700$ controls, five SNPs had suggestive evidence of interaction 
with current MHT use; but none of them reached genome-wide significance ${ }^{40}$. A meta-analysis of genome-wide caseonly studies in 2,920 cases also found no statistically significant interactions between SNPs and MHT use on breast cancer overall or by subtype ${ }^{24}$. We similarly did not find any genome-wide statistically significant interactions between genetic variants and MHT use in this study, and we further did not replicate previously suggested SNPs (data not shown).

The region for which the strongest evidence of interaction with current MHT use on breast cancer risk was observed (lead SNP rs4674019), was also implicated in the analysis restricted to combined EPT use only ( $p$-value $=4.5 \times 10^{-6}$ ). The rs4674019 SNP is an intronic variant in the coding region for the long intergenic non-protein coding RNA 607 ( $L I N C 00607$ ). Although the functionality of long non-coding RNAs is still not clear, it has been recently recognized that abnormal expression of long non-coding RNAs may play an important role in cell cycle control and cell differentiation, which is related to cancer and neurodegenerative disease ${ }^{41-43}$. Expression levels of LINC00607 were found to be significantly downregulated among lung adenocarcinoma tissues, compared to adjacent tissues ${ }^{44}$. Other GWAS have shown genetic variants in the LINC00607 gene to be associated with height in people of European ancestry ${ }^{45}$. Previous evidence for long noncoding RNAs in relation to breast cancer risk is limited; but it is possible that changes in exogenous hormone levels due to MHT use result in differential expression that eventually leads to tumorigenesis.

We also observed suggestive evidence of interaction between current use of both MHT and EPT and rs146251672. SNP rs146251672 is located in the intronic region for the prickle planar cell polarity protein 2 (PRICKLE2) gene on chromosome 3. PRICKLE2 encodes a non-canonical Wnt signaling protein that mediates feedback amplification to generate asymmetric planar cell polarity (PCP) signaling ${ }^{46}$. The Wnt pathway has been found to be activated in more than half of breast tumors, and is associated with lower overall survival for breast cancer patients ${ }^{47}$. In particular, the upregulation of the Wnt/PCP pathway has been suggested to be associated with more malignant phenotypes, such as abnormal tissue polarity, invasion and metastasis ${ }^{48}$. Exposure to estrogen has been associated with accelerated tumor formation in ER-knockout/Wnt-1 mice ${ }^{35}$. It is plausible that MHT acts partially through the alternative Wnt pathway rather than ER-dependent pathways to promote breast tumor development.

This study constitutes the largest genome-wide interaction analysis for current MHT use and breast cancer risk in postmenopausal women to date. We analyzed data from more than 62,000 women for whom we had both MHT use and genotypes from more than 9.6 million genetic variants. We controlled our analysis for potential confounding by population stratification by adjusting for principal components. We performed LD-based clumping, which accounted for correlations between genotypes to identify the strongest signal in each independent region, providing more targeted variants and regions for future investigation.

There are some limitations to our study. We used a single binary definition of current MHT use within six months prior to reference date and could not evaluate other measures such as age at MHT initiation or duration of MHT use. This could lead to some exposure misclassification, particularly for the non-population based studies, where it is possible that those cases had stopped their MHT use at time of recruitment and were classified as non-current users. Such misclassification would have attenuated the main effect of MHT and reduced our statistical power to detect any interactions. In our sensitivity analysis using population-based studies only, we found stronger interactions between the lead SNPs and MHT use. However, given a smaller sample size in the sensitivity analysis, it is possible that we did not have sufficient statistical power to detect any other potential interactions. The use of estrogen only hormone therapy (ET) was also not available among the study participants, although the statistical power might be further limited since the main association of ET and breast cancer risk is much smaller than EPT use ${ }^{5}$. In addition, our study sample only included women of European ancestry, and thus, our findings may not be generalizable to other race/ethnicity groups.

Page $13 / 23$ 
It is important to note that the lack of statistical interaction, on the log-scale, does not necessarily imply a lack of biological interaction. The results are consistent with a model in which the effects of genetic variants and MHT use combine multiplicatively on risk, which could still indicate important interactions at a functional level. Overall, our results suggest that it is not necessary to include interaction variables for $\mathrm{G} \times \mathrm{MHT}$ use in development of breast cancer risk prediction models. Although our results suggested that potential interaction effect between SNP rs4674019 and current $\mathrm{MHT}$, further validation is needed. Several suggestive interactions also warrant further investigations in independent studies.

\section{Conclusion}

In this large genome-wide SNP-MHT interaction study of breast cancer, we found no strong support for common genetic variants modifying the effect of $\mathrm{MHT}$ on breast cancer risk. These results suggest that common genetic variation has limited impact on the observed MHT-breast cancer risk association.

\section{Abbreviations}

MHT

menopausal hormone therapy

LD

linkage disequilibrium

SNP

single nucleotide polymorphism

EPT

estrogen-progesterone menopausal hormone therapy

ET

estrogen-only menopausal hormone therapy

ER+

estrogen receptor positive

GWAS

genome-wide association studies

BCAC

Breast Cancer Association Consortium

iCOGs

samples genotyped using the Illumina custom iSelect genotyping array

OncoArray

samples genotyped using the Illumina $500 \mathrm{~K}$ array

\section{Declarations}

Consent for publication: Not applicable

Availability of data and materials: The data that support the findings of this study are available from the Breast Cancer Association Consortium but restrictions apply to the availability of these data, which were used under license for the current study, and so are not publicly available. Data are however available from the authors upon reasonable request and with permission of the Breast Cancer Association Consortium.

Competing interests: The authors declare that they have no competing interests. 


\section{Funding}

BCAC is funded by Cancer Research UK [C1287/A16563, C1287/A10118], the European Union's Horizon 2020 Research and Innovation Programme (grant numbers 634935 and 633784 for BRIDGES and B-CAST respectively), and by the European Community's Seventh Framework Programme under grant agreement number 223175 (grant number HEALTHF2-2009-223175) (COGS). The EU Horizon 2020 Research and Innovation Programme funding source had no role in study design, data collection, data analysis, data interpretation or writing of the report.

Genotyping of the OncoArray was funded by the NIH Grant U19 CA148065, and Cancer UK Grant C1287/A16563 and the PERSPECTIVE project supported by the Government of Canada through Genome Canada and the Canadian Institutes of Health Research (grant GPH-129344) and, the Ministère de l'Économie, Science et Innovation du Québec through Genome Québec and the PSRSIIRI-701 grant, and the Quebec Breast Cancer Foundation. Funding for the iCOGS infrastructure came from: the European Community's Seventh Framework Programme under grant agreement $\mathrm{n}^{\circ} 223175$ (HEALTH-F2-2009-223175) (COGS), Cancer Research UK (C1287/A10118, C1287/A10710, C12292/A11174, C1281/A12014, C5047/A8384, C5047/A15007, C5047/A10692, C8197/A16565), the National Institutes of Health (CA128978) and Post-Cancer GWAS initiative (1U19 CA148537, 1U19 CA148065 and 1U19 CA148112 - the GAME-ON initiative), the Department of Defense (W81XWH-10-1-0341), the Canadian Institutes of Health Research (CIHR) for the CIHR Team in Familial Risks of Breast Cancer, and Komen Foundation for the Cure, the Breast Cancer Research Foundation, and the Ovarian Cancer Research Fund. The DRIVE Consortium was funded by U19 CA148065.

CBCS is funded by the Canadian Cancer Society (grant \# 313404) and the Canadian Institutes of Health Research. The CECILE study was supported by Fondation de France, Institut National du Cancer (INCa), Ligue Nationale contre le Cancer, Agence Nationale de Sécurité Sanitaire, de l'Alimentation, de l'Environnement et du Travail (ANSES), Agence Nationale de la Recherche (ANR). The American Cancer Society funds the creation, maintenance, and updating of the CPS-II cohort. The coordination of EPIC is financially supported by International Agency for Research on Cancer (IARC) and also by the Department of Epidemiology and Biostatistics, School of Public Health, Imperial College London which has additional infrastructure support provided by the NIHR Imperial Biomedical Research Centre (BRC). The national cohorts are supported by: Danish Cancer Society (Denmark); Ligue Contre le Cancer, Institut Gustave Roussy, Mutuelle Générale de l'Education Nationale, Institut National de la Santé et de la Recherche Médicale (INSERM) (France); German Cancer Aid, German Cancer Research Center (DKFZ), German Institute of Human Nutrition Potsdam- Rehbruecke (DIfE), Federal Ministry of Education and Research (BMBF) (Germany); Associazione Italiana per la Ricerca sul Cancro-AIRCItaly, Compagnia di SanPaolo and National Research Council (Italy); Dutch Ministry of Public Health, Welfare and Sports (VWS), Netherlands Cancer Registry (NKR), LK Research Funds, Dutch Prevention Funds, Dutch ZON (Zorg Onderzoek Nederland), World Cancer Research Fund (WCRF), Statistics Netherlands (The Netherlands); Health Research Fund (FIS) Instituto de Salud Carlos III (ISCIII), Regional Governments of Andalucía, Asturias, Basque Country, Murcia and Navarra, and the Catalan Institute of Oncology - ICO (Spain); Swedish Cancer Society, Swedish Research Council and County Councils of Skåne and Västerbotten (Sweden); Cancer Research UK (14136 to EPIC-Norfolk; C8221/A29017 to EPICOxford), Medical Research Council (1000143 to EPIC-Norfolk; MR/M012190/1 to EPIC-Oxford). (United Kingdom).The GENICA was funded by the Federal Ministry of Education and Research (BMBF) Germany grants 01KW9975/5, 01KW9976/8, 01 KW9977/0 and 01KW0114, the Robert Bosch Foundation, Stuttgart, Deutsches Krebsforschungszentrum (DKFZ), Heidelberg, the Institute for Prevention and Occupational Medicine of the German Social Accident Insurance, Institute of the Ruhr University Bochum (IPA), Bochum, as well as the Department of Internal Medicine, Evangelische Kliniken Bonn gGmbH, Johanniter Krankenhaus, Bonn, Germany. The KARMA study was supported by Märit and Hans Rausings Initiative Against Breast Cancer. The MARIE study was supported by the Deutsche Krebshilfe e.V. [70-2892-BR I, 106332, 108253, 108419, 110826, 110828], the Hamburg Cancer Society, the German Cancer Research Center (DKFZ) and the Federal Ministry of Education and Research (BMBF) Germany [01KH0402]. The MCBCS was supported by the NIH grants CA192393, CA116167, CA176785 an NIH Specialized 
Program of Research Excellence (SPORE) in Breast Cancer [CA116201], and the Breast Cancer Research Foundation and a generous gift from the David F. and Margaret T. Grohne Family Foundation. The Melbourne Collaborative Cohort Study (MCCS) cohort recruitment was funded by VicHealth and Cancer Council Victoria. The MCCS was further augmented by Australian National Health and Medical Research Council grants 209057, 396414 and 1074383 and by infrastructure provided by Cancer Council Victoria. Cases and their vital status were ascertained through the Victorian Cancer Registry and the Australian Institute of Health and Welfare, including the National Death Index and the Australian Cancer Database. The MEC was supported by NIH grants CA63464, CA54281, CA098758, CA132839 and CA164973. The MISS study is supported by funding from ERC-2011-294576 Advanced grant, Swedish Cancer Society, Swedish Research Council, Local hospital funds, Berta Kamprad Foundation, Gunnar Nilsson. The MMHS study was supported by NIH grants CA97396, CA128931, CA116201, CA140286 and CA177150. The Carolina Breast Cancer Study (NCBCS) was funded by Komen Foundation, the National Cancer Institute (P50 CA058223, U54 CA156733, U01 CA179715), and the North Carolina University Cancer Research Fund. The NHS was supported by NIH grants P01 CA87969, UM1 CA186107, and U19 CA148065. The NHS2 was supported by NIH grants UM1 CA176726 and U19 CA148065. The PBCS was funded by Intramural Research Funds of the National Cancer Institute, Department of Health and Human Services, USA. Genotyping for PLCO was supported by the Intramural Research Program of the National Institutes of Health, $\mathrm{NCl}$, Division of Cancer Epidemiology and Genetics. The PLCO is supported by the Intramural Research Program of the Division of Cancer Epidemiology and Genetics and supported by contracts from the Division of Cancer Prevention, National Cancer Institute, National Institutes of Health. PROCAS is funded from NIHR grant PGfAR 0707-10031. The SASBAC study was supported by funding from the Agency for Science, Technology and Research of Singapore (A*STAR), the US National Institute of Health $(\mathrm{NIH})$ and the Susan G. Komen Breast Cancer Foundation. The SMC is funded by the Swedish Cancer Foundation and the Swedish Research Council (VR 2017-00644) grant for the Swedish Infrastructure for Medical Population-based Life-course Environmental Research (SIMPLER). The UCIBCS component of this research was supported by the NIH [CA58860, CA92044] and the Lon V Smith Foundation [LVS39420]. The UKBGS is funded by Breast Cancer Now and the Institute of Cancer Research (ICR), London. ICR acknowledges NHS funding to the NIHR Biomedical Research Centre. The USRT Study was funded by Intramural Research Funds of the National Cancer Institute, Department of Health and Human Services, USA. The WHI program is funded by the National Heart, Lung, and Blood Institute, the US National Institutes of Health and the US Department of Health and Human Services (HHSN268201100046C, HHSN268201100001C, HHSN268201100002C, HHSN268201100003C, HHSN268201100004C and HHSN271201100004C). This work was also funded by NCI U19 CA148065-01.

\section{Authors' contributions:}

XW and SL formed the research proposal, analyzed and interpreted the data. XW, SL, PMK, PLA, RLM, RK and JCC were major contributors in writing the manuscript. JD, AMD, QW, ML, KM, MKB, KJA, RAM, AB, DGL, EC, PG, TT, CM, LRT, AVP, LD, RK, RH, WYL, TB, UH, KC, MG, PH, MK, AJ, HB, FJC, NLL, JEO, KJR, GGG, RJM, MCS, LLM, LRW, CAH, HO, AA, UK, PW, CS, SJW, CMV, CMP, AFO, MAT, DJH, AHE, RMT, KB, ILA, JF, SJC, TUA, MGC, DGE, WGN, EMV, AH, AW, NH, HAC, AZ, MEJ, NO, MJS, AJS, CMK, ML, RLP, DFE collected and provided genotyping and epidemiologic data, and provided comments on the manuscript. All authors read and approved the final manuscript.

\section{Acknowledgements}

We thank all the individuals who took part in these studies and all the researchers, clinicians, technicians and administrative staff who have enabled this work to be carried out. The COGS study would not have been possible without the contributions of the following: Andrew Lee, and Ed Dicks, Craig Luccarini and the staff of the Centre for Genetic Epidemiology Laboratory, Javier Benitez, Anna Gonzalez-Neira and the staff of the CNIO genotyping unit, Jacques Simard and Daniel C. Tessier, Francois Bacot, Daniel Vincent, Sylvie LaBoissière and Frederic Robidoux and the staff of the McGill University and Génome Québec Innovation Centre, Stig E. Bojesen, Sune F. Nielsen, Borge G. 
Nordestgaard, and the staff of the Copenhagen DNA laboratory, and Julie M. Cunningham, Sharon A. Windebank, Christopher A. Hilker, Jeffrey Meyer and the staff of Mayo Clinic Genotyping Core Facility. ABCFS thank Maggie Angelakos, Judi Maskiell, Gillian Dite. CBCS thanks study participants, co-investigators, collaborators and staff of the Canadian Breast Cancer Study, and project coordinators Agnes Lai and Celine Morissette. Investigators from the CPS-II cohort thank the participants and Study Management Group for their invaluable contributions to this research. They also acknowledge the contribution to this study from central cancer registries supported through the Centers for Disease Control and Prevention National Program of Cancer Registries, as well as cancer registries supported by the National Cancer Institute Surveillance Epidemiology and End Results program. We thank the participants and the investigators of EPIC (European Prospective Investigation into Cancer and Nutrition). The GENICA Network: Dr. Margarete Fischer-BoschInstitute of Clinical Pharmacology, Stuttgart, and University of Tübingen, Germany [Hiltrud Brauch, WYL, RH], German Cancer Consortium (DKTK) and German Cancer Research Center (DKFZ), Partner Site Tübingen [Hiltrud Brauch], Deutsche Forschungsgemeinschaft (DFG, German Research Foundation) under Germany\&\#39;s Excellence Strategy EXC 2180 - 390900677 [Hiltrud Brauch], Department of Internal Medicine, Evangelische Kliniken Bonn gGmbH, Johanniter Krankenhaus, Bonn, Germany [Yon-Dschun Ko, Christian Baisch], Institute of Pathology, University of Bonn, Germany [Hans-Peter Fischer], Molecular Genetics of Breast Cancer, Deutsches Krebsforschungszentrum (DKFZ), Heidelberg, Germany [UH], Institute for Prevention and Occupational Medicine of the German Social Accident Insurance, Institute of the Ruhr University Bochum (IPA), Bochum, Germany [TB, Beate Pesch, Sylvia Rabstein, Anne Lotz]; and Institute of Occupational Medicine and Maritime Medicine, University Medical Center Hamburg-Eppendorf, Germany [Volker Harth]. KARMA and SASBAC thank the Swedish Medical Research Counsel. MARIE thanks Petra Seibold, Dieter Flesch-Janys, Judith Heinz, Nadia Obi, Alina Vrieling, Sabine Behrens, Ursula Eilber, Muhabbet Celik, Til Olchers and Stefan Nickels. The MCCS was made possible by the contribution of many people, including the original investigators, the teams that recruited the participants and continue working on follow-up, and the many thousands of Melbourne residents who continue to participate in the study. We thank the coordinators, the research staff and especially the MMHS participants for their continued collaboration on research studies in breast cancer. MSKCC thanks Marina Corines, Lauren Jacobs. 'For NHS and NHS2 the study protocol was approved by the institutional review boards of the Brigham and Women's Hospital and Harvard T.H. Chan School of Public Health, and those of participating registries as required. We would like to thank the participants and staff of the NHS and NHS2 for their valuable contributions as well as the following state cancer registries for their help: AL, AZ, AR, CA, CO, CT, DE, FL, GA, ID, IL, IN, IA, KY, LA, ME, MD, MA, MI, NE, NH, NJ, NY, NC, ND, OH, OK, OR, PA, RI, SC, TN, TX, VA, WA, WY. The authors assume full responsibility for analyses and interpretation of these data. The OFBCR thanks Teresa Selander, Nayana Weerasooriya and Steve Gallinger. ORIGO thanks E. Krol-Warmerdam, and J. Blom for patient accrual, administering questionnaires, and managing clinical information. The LUMC survival data were retrieved from the Leiden hospital-based cancer registry system (ONCDOC) with the help of Dr. J. Molenaar. PBCS thanks Louise Brinton, Mark Sherman, Neonila SzeszeniaDabrowska, Beata Peplonska, Witold Zatonski, Pei Chao, Michael Stagner. PROCAS thanks NIHR for funding. UCIBCS thanks Irene Masunaka. UKBGS thanks Breast Cancer Now and the Institute of Cancer Research for support and funding of the Generations Study, and the study participants, study staff, and the doctors, nurses and other health care providers and health information sources who have contributed to the study. We acknowledge NHS funding to the Royal Marsden/ICR NIHR Biomedical Research Centre. We acknowledge funding to the Manchester NIHR Biomedical Research Centre (IS-BRC-1215-20007). The authors thank the WHI investigators and staff for their dedication and the study participants for making the program possible.

\section{Authors' information}

Disclaimer: Where authors are identified as personnel of the International Agency for Research on Cancer / World Health Organization, the authors alone are responsible for the views expressed in this article and they do not necessarily represent the decisions, policy or views of the International Agency for Research on Cancer / World Health.

Page $17 / 23$ 


\section{References}

1. Siegel RL, Miller KD, Jemal A. Cancer statistics, 2019. CA Cancer J Clin 2019;69: 7-34.

2. Chlebowski RT, Kuller LH, Prentice RL, Stefanick ML, Manson JE, Gass M, Aragaki AK, Ockene JK, Lane DS, Sarto GE, Rajkovic A, Schenken R, et al. Breast cancer after use of estrogen plus progestin in postmenopausal women. $N$ Engl $J$ Med 2009;360: 573-87.

3. Prentice RL, Chlebowski RT, Stefanick ML, Manson JE, Langer RD, Pettinger M, Hendrix SL, Hubbell FA, Kooperberg C, Kuller LH, Lane DS, McTiernan A, et al. Conjugated equine estrogens and breast cancer risk in the Women's Health Initiative clinical trial and observational study. Am J Epidemio/ 2008;167: 1407-15.

4. Anothaisintawee T, Wiratkapun C, Lerdsitthichai P, Kasamesup V, Wongwaisayawan S, Srinakarin J, Hirunpat S, Woodtichartpreecha P, Boonlikit S, Teerawattananon Y, Thakkinstian A. Risk factors of breast cancer: a systematic review and meta-analysis. Asia Pac J Public Health 2013;25: 368-87.

5. Collaborative Group on Hormonal Factors in Breast C. Type and timing of menopausal hormone therapy and breast cancer risk: individual participant meta-analysis of the worldwide epidemiological evidence. Lancet 2019;394: 1159-68.

6. Breast cancer and hormone replacement therapy: collaborative reanalysis of data from 51 epidemiological studies of 52,705 women with breast cancer and 108,411 women without breast cancer. Collaborative Group on Hormonal Factors in Breast Cancer. Lancet 1997;350: 1047-59.

7. Beral V, Reeves G, Bull D, Green J, Million Women Study C. Breast cancer risk in relation to the interval between menopause and starting hormone therapy. J Natl Cancer Inst 2011;103: 296-305.

8. Chen WY, Hankinson SE, Schnitt SJ, Rosner BA, Holmes MD, Colditz GA. Association of hormone replacement therapy to estrogen and progesterone receptor status in invasive breast carcinoma. Cancer 2004;101: 1490-500.

9. Gertig DM, Fletcher AS, English DR, Macinnis RJ, Hopper JL, Giles GG. Hormone therapy and breast cancer: what factors modify the association? Menopause 2006;13: 178-84.

10. Salagame U, Banks E, O'Connell DL, Egger S, Canfell K. Menopausal Hormone Therapy use and breast cancer risk by receptor subtypes: Results from the New South Wales Cancer Lifestyle and EvaluAtion of Risk (CLEAR) study. PLoS One 2018;13: e0205034.

11. Saxena T, Lee E, Henderson KD, Clarke CA, West D, Marshall SF, Deapen D, Bernstein L, Ursin G. Menopausal hormone therapy and subsequent risk of specific invasive breast cancer subtypes in the California Teachers Study. Cancer Epidemiol Biomarkers Prev 2010;19: 2366-78.

12. Setiawan VW, Monroe KR, Wilkens LR, Kolonel LN, Pike MC, Henderson BE. Breast cancer risk factors defined by estrogen and progesterone receptor status: the multiethnic cohort study. Am J Epidemiol 2009;169: 1251-9.

13. Mello ML, Vidal BC, Russo IH, Lareef MH, Russo J. DNA content and chromatin texture of human breast epithelial cells transformed with 17-beta-estradiol and the estrogen antagonist ICI 182,780 as assessed by image analysis. Mutat Res 2007;617: 1-7.

14. Saeed M, Rogan E, Fernandez SV, Sheriff F, Russo J, Cavalieri E. Formation of depurinating N3Adenine and N7Guanine adducts by MCF-10F cells cultured in the presence of 4-hydroxyestradiol. Int J Cancer 2007;120: 1821-4. 
15. Persson I. Estrogens in the causation of breast, endometrial and ovarian cancers - evidence and hypotheses from epidemiological findings. J Steroid Biochem Mol Biol 2000;74: 357-64.

16. Yager JD, Liehr JG. Molecular mechanisms of estrogen carcinogenesis. Annu Rev Pharmacol Toxico/ 1996;36: 20332.

17. Easton DF, Pooley KA, Dunning AM, Pharoah PD, Thompson D, Ballinger DG, Struewing JP, Morrison J, Field H, Luben R, Wareham N, Ahmed S, et al. Genome-wide association study identifies novel breast cancer susceptibility loci. Nature 2007;447: 1087-93.

18. Hunter DJ, Kraft P, Jacobs KB, Cox DG, Yeager M, Hankinson SE, Wacholder S, Wang Z, Welch R, Hutchinson A, Wang $\mathrm{J}, \mathrm{Yu} \mathrm{K}$, et al. A genome-wide association study identifies alleles in FGFR2 associated with risk of sporadic postmenopausal breast cancer. Nat Genet 2007;39: 870-4.

19. Michailidou K, Lindstrom S, Dennis J, Beesley J, Hui S, Kar S, Lemacon A, Soucy P, Glubb D, Rostamianfar A, Bolla MK, Wang Q, et al. Association analysis identifies 65 new breast cancer risk loci. Nature 2017;551: $92-4$.

20. Prentice RL, Huang Y, Hinds DA, Peters U, Pettinger M, Cox DR, Beilharz E, Chlebowski RT, Rossouw JE, Caan B, Ballinger DG. Variation in the FGFR2 gene and the effects of postmenopausal hormone therapy on invasive breast cancer. Cancer Epidemiol Biomarkers Prev 2009;18: 3079-85.

21. Ghoussaini M, Edwards SL, Michailidou K, Nord S, Cowper-Sal Lari R, Desai K, Kar S, Hillman KM, Kaufmann S, Glubb DM, Beesley J, Dennis J, et al. Evidence that breast cancer risk at the 2q35 locus is mediated through IGFBP5 regulation. Nat Commun 2014;4: 4999.

22. Nickels S, Truong T, Hein R, Stevens K, Buck K, Behrens S, Eilber U, Schmidt M, Haberle L, Vrieling A, Gaudet M, Figueroa J, et al. Evidence of gene-environment interactions between common breast cancer susceptibility loci and established environmental risk factors. PLoS Genet 2013;9: e1003284.

23. Kapoor PM, Lindstrom S, Behrens S, Wang X, Michailidou K, Bolla MK, Wang Q, Dennis J, Dunning AM, Pharoah PDP, Schmidt MK, Kraft P, et al. Assessment of interactions between 205 breast cancer susceptibility loci and 13 established risk factors in relation to breast cancer risk, in the Breast Cancer Association Consortium. Int J Epidemio/ 2020;49: 21632.

24. Rudolph A, Hein R, Lindstrom S, Beckmann L, Behrens S, Liu J, Aschard H, Bolla MK, Wang J, Truong T, CordinaDuverger E, Menegaux F, et al. Genetic modifiers of menopausal hormone replacement therapy and breast cancer risk: a genome-wide interaction study. Endocr Relat Cancer 2013;20: 875-87.

25. Michailidou K, Beesley J, Lindstrom S, Canisius S, Dennis J, Lush MJ, Maranian MJ, Bolla MK, Wang Q, Shah M, Perkins BJ, Czene K, et al. Genome-wide association analysis of more than 120,000 individuals identifies 15 new susceptibility loci for breast cancer. Nat Genet 2015;47: 373-80.

26. Michailidou K, Hall P, Gonzalez-Neira A, Ghoussaini M, Dennis J, Milne RL, Schmidt MK, Chang-Claude J, Bojesen SE, Bolla MK, Wang Q, Dicks E, et al. Large-scale genotyping identifies 41 new loci associated with breast cancer risk. Nat Genet 2013;45: 353-61, 61e1-2.

27. Amos Cl, Dennis J, Wang Z, Byun J, Schumacher FR, Gayther SA, Casey G, Hunter DJ, Sellers TA, Gruber SB, Dunning AM, Michailidou K, et al. The OncoArray Consortium: A Network for Understanding the Genetic Architecture of Common Cancers. Cancer Epidemiol Biomarkers Prev 2017;26: 126-35. 
28. 1000 Genomes Project C, Auton A, Brooks LD, Durbin RM, Garrison EP, Kang HM, Korbel JO, Marchini JL, McCarthy S, McVean GA, Abecasis GR. A global reference for human genetic variation. Nature 2015;526: 68-74.

29. Price AL, Patterson NJ, Plenge RM, Weinblatt ME, Shadick NA, Reich D. Principal components analysis corrects for stratification in genome-wide association studies. Nat Genet 2006;38: 904-9.

30. Jiao S, Hsu L, Hutter CM, Peters U. The use of imputed values in the meta-analysis of genome-wide association studies. Genet Epidemiol 2011;35: 597-605.

31. Willer CJ, Li Y, Abecasis GR. METAL: fast and efficient meta-analysis of genomewide association scans.

Bioinformatics 2010;26: 2190-1.

32. Rossouw JE, Anderson GL, Prentice RL, LaCroix AZ, Kooperberg C, Stefanick ML, Jackson RD, Beresford SA, Howard $\mathrm{BV}$, Johnson KC, Kotchen JM, Ockene J, et al. Risks and benefits of estrogen plus progestin in healthy postmenopausal women: principal results From the Women's Health Initiative randomized controlled trial. JAMA 2002;288: 321-33.

33. Russo J, Russo IH. The role of estrogen in the initiation of breast cancer. J Steroid Biochem Mol Biol 2006;102: 8996.

34. Cavalieri E, Chakravarti D, Guttenplan J, Hart E, Ingle J, Jankowiak R, Muti P, Rogan E, Russo J, Santen R, Sutter T. Catechol estrogen quinones as initiators of breast and other human cancers: implications for biomarkers of susceptibility and cancer prevention. Biochim Biophys Acta 2006;1766: 63-78.

35. Yue W, Wang JP, Li Y, Fan P, Liu G, Zhang N, Conaway M, Wang H, Korach KS, Bocchinfuso W, Santen R. Effects of estrogen on breast cancer development: Role of estrogen receptor independent mechanisms. Int J Cancer 2010;127: 1748-57.

36. Horwitz KB, Sartorius CA. Progestins in hormone replacement therapies reactivate cancer stem cells in women with preexisting breast cancers: a hypothesis. J Clin Endocrinol Metab 2008;93: 3295-8.

37. Santen RJ. Risk of breast cancer with progestins: critical assessment of current data. Steroids 2003;68: 953-64.

38. Harlid S, Butt S, Ivarsson MI, Eyfjord JE, Lenner P, Manjer J, Dillner J, Carlson J. Interactive effect of genetic susceptibility with height, body mass index, and hormone replacement therapy on the risk of breast cancer. $B M C$ Womens Health 2012;12: 17.

39. Travis RC, Reeves GK, Green J, Bull D, Tipper SJ, Baker K, Beral V, Peto R, Bell J, Zelenika D, Lathrop M, Million Women Study C. Gene-environment interactions in 7610 women with breast cancer: prospective evidence from the Million Women Study. Lancet 2010;375: 2143-51.

40. Hein R, Flesch-Janys D, Dahmen N, Beckmann L, Lindstrom S, Schoof N, Czene K, Mittelstrass K, Illig T, Seibold P, Behrens S, Humphreys $\mathrm{K}$, et al. A genome-wide association study to identify genetic susceptibility loci that modify ductal and lobular postmenopausal breast cancer risk associated with menopausal hormone therapy use: a two-stage design with replication. Breast Cancer Res Treat 2013;138: 529-42.

41. Dey BK, Mueller AC, Dutta A. Long non-coding RNAs as emerging regulators of differentiation, development, and disease. Transcription 2014;5: e944014.

42. Ricciuti B, Mencaroni C, Paglialunga L, Paciullo F, Crino L, Chiari R, Metro G. Long noncoding RNAs: new insights into non-small cell lung cancer biology, diagnosis and therapy. Med Oncol 2016;33: 18.

Page 20/23 
43. Zhao W, An Y, Liang Y, Xie XW. Role of HOTAIR long noncoding RNA in metastatic progression of lung cancer. Eur Rev Med Pharmacol Sci 2014;18: 1930-6.

44. Zhao B, Xu H, Ai X, Adalat Y, Tong Y, Zhang J, Yang S. Expression profiles of long noncoding RNAs in lung adenocarcinoma. Onco Targets Ther 2018;11: 5383-90.

45. Kichaev G, Bhatia G, Loh PR, Gazal S, Burch K, Freund MK, Schoech A, Pasaniuc B, Price AL. Leveraging Polygenic Functional Enrichment to Improve GWAS Power. Am J Hum Genet 2019;104: 65-75.

46. Tree DR, Shulman JM, Rousset R, Scott MP, Gubb D, Axelrod JD. Prickle mediates feedback amplification to generate asymmetric planar cell polarity signaling. Cell 2002;109: 371-81.

47. Khramtsov Al, Khramtsova GF, Tretiakova M, Huo D, Olopade OI, Goss KH. Wnt/beta-catenin pathway activation is enriched in basal-like breast cancers and predicts poor outcome. Am J Pathol 2010;176: 2911-20.

48. Katoh M. WNT/PCP signaling pathway and human cancer (review). Oncol Rep 2005;14: 1583-8.

\section{Figures}



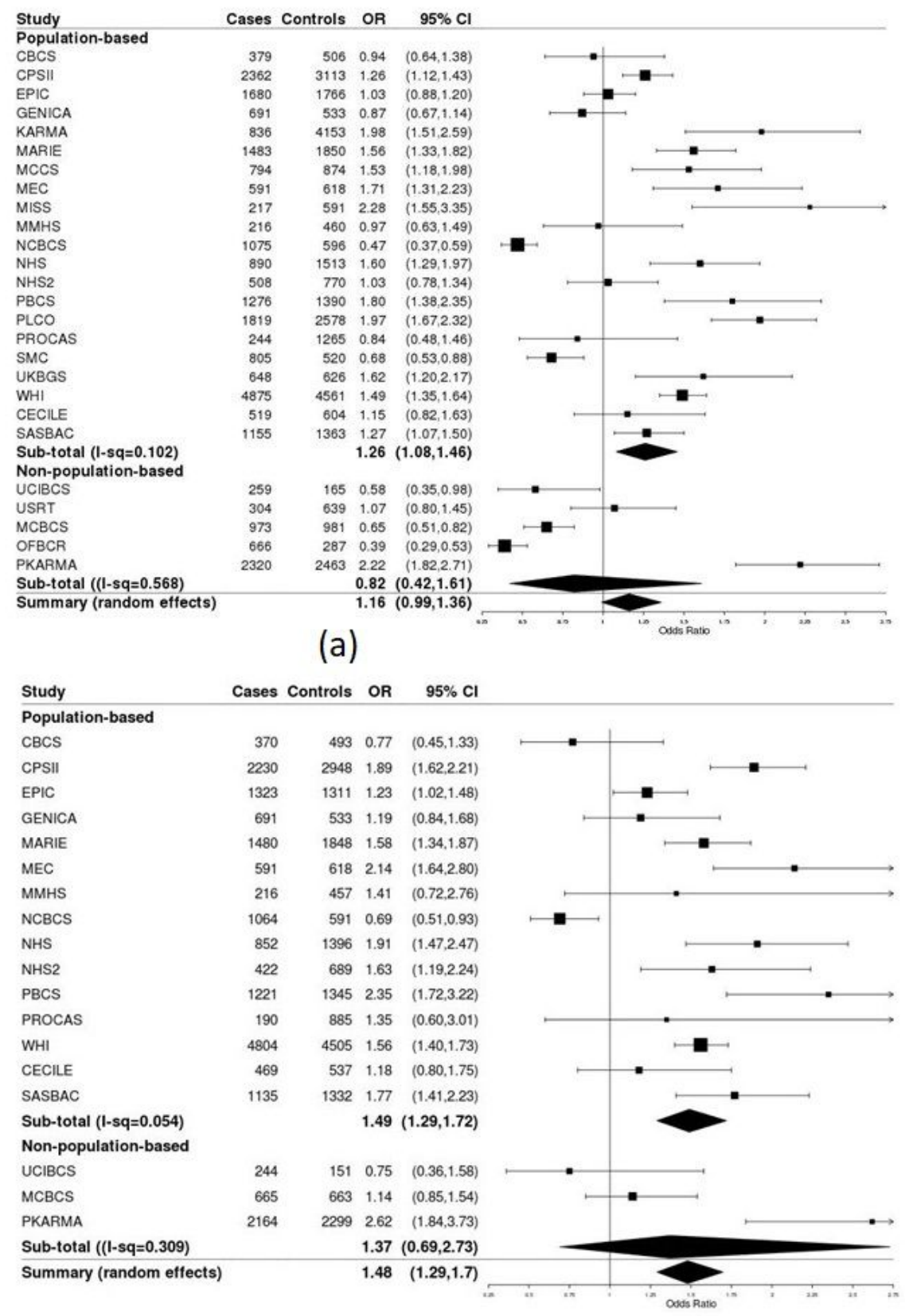

(b)

Figure 1

Main effects of current menopausal hormone therapy use and breast cancer risk by study A) Current use of any menopausal hormone therapy B) Current use of combined estrogen-progesterone menopausal hormone therapy 


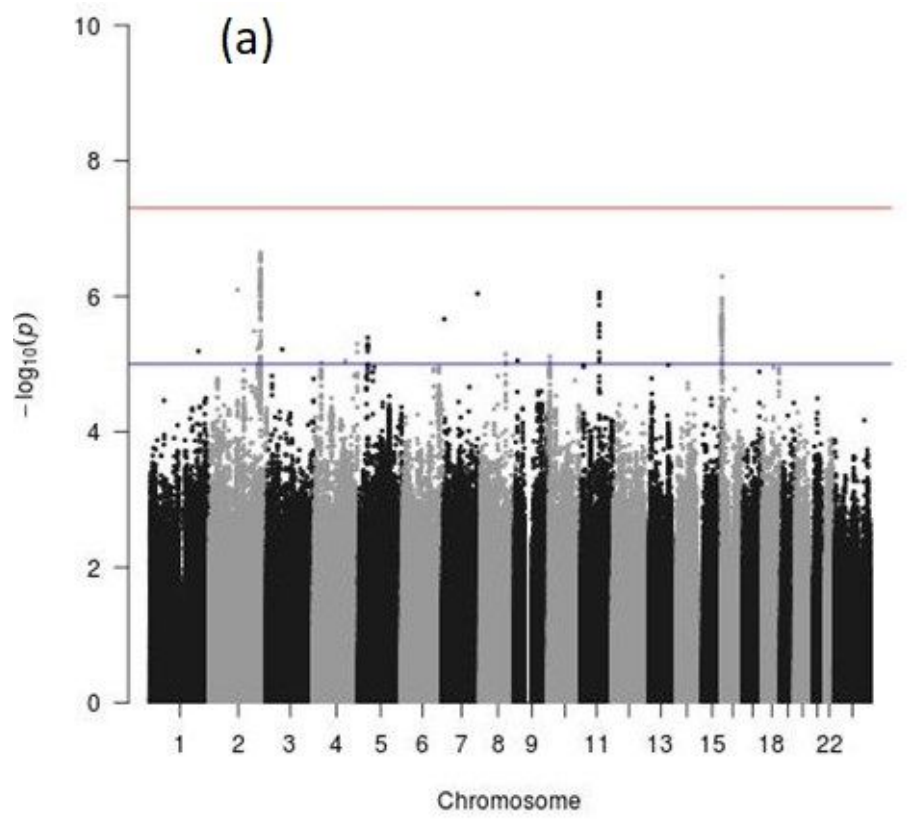

(b)

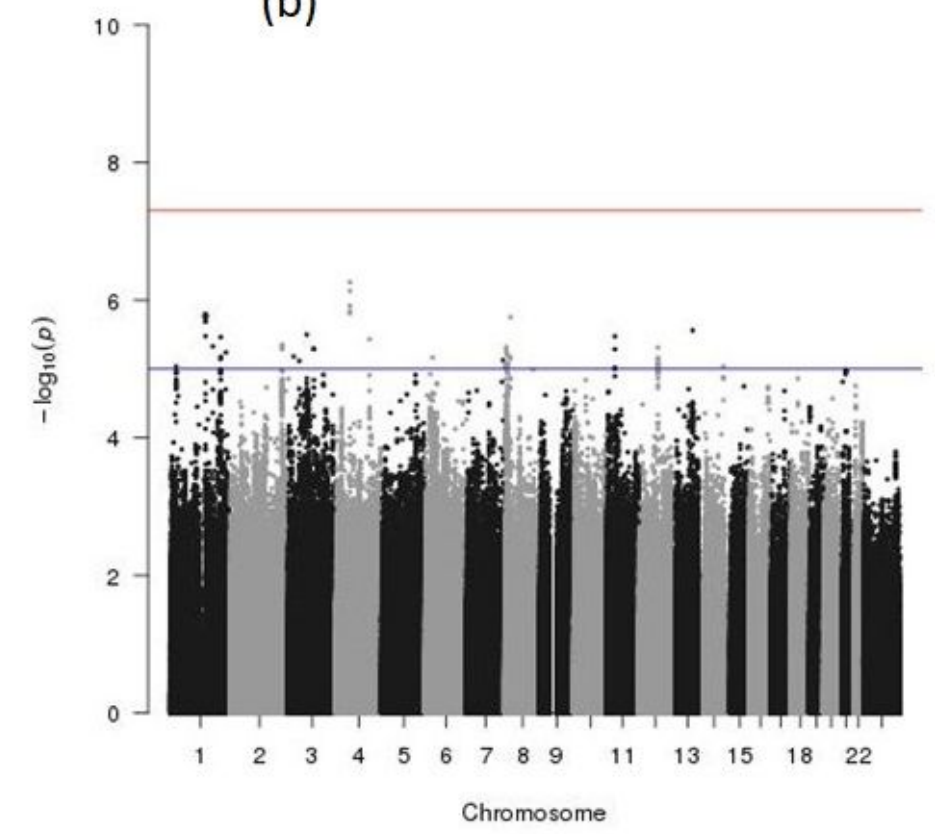

Figure 2

Manhattan plot of genome-wide interaction of current use of menopausal hormone therapy on breast cancer risk $A$ ) Current MHT use B) Current EPT use * Red line: log-transformed genome-wide significant threshold at 5x10-8; Blue line: log-transformed suggestive threshold at 1×10-5.

\section{Supplementary Files}

This is a list of supplementary files associated with this preprint. Click to download.

- GWASxMHTSupplementalMaterial.docx 